Radojka M. Vukčević

Filološki fakultet

Studentski trg 3 Beograd
821.163.41.09-1 Петровић Његош П. ІІ doi 10.18485/analiff.2015.27.2.1

\title{
NAJNOVIJA RECEPCIJA NJEGOŠA U SAD: 1995-2010
}

U radu se istražuju putevi recepcije Njegoša i njegovih djela u Sjedinjenim američkim državama u periodu od 1995. godine do 2010. Ovaj period je odabran s ciljem da se nastavi istraživanje Svetozara Koljevića o recepciji Njegoša u prethodnom periodu koje je predstavljeno u njegovoj studiji Njegoš u engleskoj $i$ američkoj kulturi. Ispitaće se recepcija prevoda Njegoševih djela i ostali doprinosi američkih istraživača: prikazi, kritike i pomeni od značaja za ovaj petnaestogodišnji period. Primjeniće se hronološki metod i ocjeniće se doprinos kako američkih istraživača tako i istaknutih slavista našeg porijekla koji su dali poseban doprinos recepciji Njegoša u Americi. ka, religija

Ključne riječi: recepcija, Njegoš, SAD, američka kultura, istorija, politi-

U okviru komparativnog proučavanja književnosti, istraživanje recepcije, ima dugu tradiciju, kako u svijetu tako i kod nas. Naša književnost, kao ,pripadnik kruga takozvanih malih kultura, odnosno područja delovanja jezika niske rasprostranjenosti, prirodno, oduvek je bila zahvalan recepijent, spremno prihvatajući i apsorbujući dostignuća svetske literature i reagujuči na njih, ponekad možda sa izvesnim zakašnjenjem, ali vazda sa osbenom, samosvojnom i razvijenom kritičkom svešću“. (Ignjačević, 1997: 299) Na to nas podsjeća Svetozar Ignjačević u tekstu „Naša recepcija afričke književnosti engleskog izraza“ da bi zaključio da je izučavanje prisustva stranih književnosti u našoj kulturi najčešće rezultat rada na magistarskim i doktorskim disertacijama, što ne znači da nema prostora za dalja istraživanja iako je osnovno polje ,uglavnom premereženo, a metodološki problemi u najvećoj meri raščišćeni, tako da ostaje samo da se popunjavaju uočene praznine i s vremena na vreme, u hodu, vrše inovacije i eventualna prevrednovanja, u skladu s novim dostignućima nauke o književnosti.“ (1997: 299)

Posmatrano iz suprotnog smjera, srpski jezik, srpska i crnogorska kultura neće naići na tako zahvalne recepijente u anglosaksonskim kultu- 
rama koji bi spremno na nju reagovali, što nam pokazuje Svetozar Koljević u svojoj preglednoj i iscrpnoj studiji Njegoš u engleskoj i američkoj kulturi (Koljević, 1999: 155-159) u kojoj daje hronološki pregled recepcije Njegoša, koja u akademskom smislu počinje sa pojavom pouzdanog prevoda Gorskog vijenca američkog slaviste Vase D. Mihailovića (1986) i izuzeno vrijedne studije britanskog slaviste Edvarda Denisa Goja (Goy, E. D) Sablja i pjesna (1995). Svi prethodni tekstovi o Njegošu samo su pomeni i u sjenci su, kako Koljević kaže: ,veoma živopisnih, često egzotičnih, političkih i kulturoloških pristupa njegovoj ličnosti u engleskoj i američkoj kulturi“". (1999: 7) U poglavlju „U novom ruhu i novim rasvetljenjima“ Svetozar Koljević ističe pojavu niza engleskih prevoda Njegoševih djela, posebno naglasivši da interesovanje za njih nikada nije izašlo izvan akademskih okvira, imajući na umu prije svega slavističke studije. Naravno, postoji i izvjesna sličnost kada se razmatraju suprotni smjerovi recepcije naše književnosti. Ulogu akademske sredine za uspon recepcije Njegoša u engleskoj i američkoj sredini Koljević ponovo ističe u zaključku svoje studije, kada ponovo piše o Gojinim ogledima u pomenutoj studiji Sablja i pjesna i kada ih vrednuje kao vrhunac razumevanja i promišljanja Njegoša i njegovog dela u engleskoj kulturi izmedju ostalog, kako kaže, i ,stoga što naznačuju savremenu sliku Njegoša kao velikog i relevantnog evropskog pesnika.“ (1999: 155)

Gojeva Sablja i pjesna pojavila se 1995. godine na kraju perioda u kome Njegoš ima najjaču recepciju u Engleskoj i SAD, što Koljević objašnjava većom akademskom obavještenošću, razvojem slavistike, radovima engleskih i američkih slavista (6 izdanja Gorskog vijenca na engleskom jeziku, 2 izdanja prevoda Vase D. Mihailovića, 4 izdanja prevoda Luče Mikrokozma, izbori Njegoševe poezije za studente). Koljević izdvaja još dvije nezaobilazne studije za ispitivanje tokova recepcije Njegoša u Americi: Đilasovu knjigu Njegoš: pjesnik, vladar, vladika, objavljenu na engleskom jeziku u Americi 1966. godine i studiju Žike Prvulovićeva o Njegoševoj religioznoj misli. On s pravom zaključuje da Njegoš i njegovo djelo i dalje predstavljaju izazov za istraživanje najrazličitijih stavova i pozicija u engleskoj i američkoj književnosti, što je bilo od posebnog značaja kada se u uzme u obzir 2013. godinu kada smo obilježili 200 godina od njegovog rođenja, a što je i nas obavezala da u narednim poglavljima pokušamo da ispitamo kojim putevima su krenuli tokovi recepcije njegovih djela u Americi u periodu od te ključne 2005 godine.

Ta ključna godina za noviju recepciju Njegoševih djela pokazala nam je da su recepcijski tokovi od tada, koliko god u pojedinostima složeni i 
često neuhvatljivi, krenuli različitim kolosjecima i pokazali isto tako različit stepen međuzavisnosti. Neke staze su se suzile, kao ona najčešća kojom put jedne književnosti u drugu nacionalnu i jezičku sredinu pravi prve kontakte posredstvom prevoda, dok su se otvorile neke nove kao ona koja ispituje savremenu istoriju, politiku ili kulturu u kojoj definisanje identiteta ima izuzetno značajno mjesto. Ranije utabane staze kojima su se kretali recepcijski tokovi u kojima su dominirali prikazi, kritike, sociolingvistički ili popularni tekstovi i dalje opstaju u ovom gotovo dvodecenijskom periodu. Akcenat se, medjutim, još snažnije pomjera sa književnog na politiku, istoriju i kulturu i time izbacuje raniju egzotiku iz igre! Ovo dovodi do daljeg izvrtanja poznatog recepcijskog obrasca: od prevoda, preko bližeg upoznavanja sa izborom najreprezentativnijih djela i konačno sintetičkih panoranskih pregleda i antologija. Destabiizuje se i u uloga kritike čija je uloga da prati prevodilaštvo „u procesu prihvatanja i uklapanja tog novog kulturnog fenomena u vlastitu tradiciju“ (Ignjačević, 1999: 306) tako da bi spoj ove dvije umjetnosti riječi (tekst i prevodjenje) mogao dovesti do uticaja ili, savremenim rečnikom definisano, do genetsko-tipoloških veza među literaturama.

Recepcijski tok u kome dominiraju prikazi, pomeni, bilješke, pokazuje da su prikazi tekstova o Njegošu i njegovom djelu veoma prisutni u ovom periodu i da već od 1995. godine počinju pohvalama već pomenute studije Edvarda Goja iz pera proslavljenog Vase D. Mihailovića, uglednog slaviste, koji je veoma zaslužan za recepciju Njegoševih djela u Americi. Te iste godine Vasa D. Mihailović daje i pregled južnoslovenskih pisaca prije 2. svetskog rata (Dictionary of Literary Bigraphy, v. 147) u koji uvrštava Njegoša. U ovaj recepcijski tok mogli bismo svrstati i veliki broj kratkih osvrta na Njegoša i njegovo djelo, kao što su npr. par stranica u knjizi Pjevač nastavlja priču (The Singer Resumes the Tale) koju su uredili Albert Lord i Meri Luiz Lord, 1995. Godine. Iste godine Zdenko Zlatar pominje Njegoša u knjizi o Gundulićevom Osmanu. To isto čini i Džon. K. Koks (John K. Cox) u svojoj studiji Istorija Srba (The History of Serbia, Harvard University Press, 2002). Emili G. Balić (Emily G. Balic) nalazi mjesto Njegošu u Enciklopediji savremene politike hrišćanstva (Encyclopedia of Modern Christian Politics) 2006. godine, dok će to isto uraditi Ronela Aleksander (Alexander Ronell) te iste godine u knjizi Bosanski, hrvatski, srpski, gramatika: sa sociolingvističkim komentarima (Bosnian, Croatian, Serbian, a grammar: with sociolingvistic commentary). Gorski vijenac će biti pomenut I u studiji Lorens Mičel (Lawrence Mitchell), 
2010. godine. Dvije godine kasnije i Momir Tomić objaviće kraći tekst o Njegošu u časopisu Srpski svijet (Serbian World).

Recepcijski tok u kome dominira književna kritika u ovom periodu nešto je bogatiji i u njemu se izdvaja komparativna studija Rolanda Klarka (Roland Clark) "Mračna strana kod Njegoša i Miltona” („The Dark Side in Njegoš and Milton") u knjizi koju su uredili Margaret H. Besingžer (Margaret H. Beissinger) i grupa autora: Epska tradicija u savremenom svijetu: poetika zajednice (Epic Traditions in the Contemporary World: The Poetics of Community,1999). Drugi značajan esej „, Petar II Petrović Njegoš: pjesnik, vladar, vladika” (, Petar II Petrović Njegoš: poet, prince, bishop) Džordža Vid Tomaševića pojavljuje se godinu dana kasnije u okviru studije Portreti srpskih arhivista (Portraits of Serbian Archivers), koju je izdala Sofija Škorić u okviru svoje izdavačke kuće Srpska književna zadruga (Serbian Literary Company). Još jedan proslavljeni izdavač, Vilijam Jovanović, oglašava se kritikom Njegoševih djela Luča mikrokozma i Gorski vijenac u svojim memoarima: Ćud Zapada: memoari Vilijama Jovanovića (The Temper of the West: A Memoir/William Jovanovich) 2003. godine. O Gorskom vijencu i Njegošu kao ocu srpske poezije devetnaestog vijeka moguće je nešto saznati iz zbornika Nacija, jezik i etika prevođenja (Nation, Language and the Ethics of Translation), koji su 2005. godine uredili Sandra Berman i Majkl Vud (Sandra Bermann i Michael Wood). Tu je i jedan raniji tekst Alberta B. Lorda "Obnova nacionalnih književnosti devetnaestog vijeka: Karadžić, Njegoš, Radičević, Ilirci i Prešern" („The nineteenth-century revival of national literatures: Karadzić, Njegoš, Radičević, the Illyrians, and Prešern”), objavljen u studiji Pregled nacionalnih književnosti: odabrani eseji (1970-2001): najnovije i zapostavljene nacionalne književnosti" (Review of National Literatures, Selected Essays, 1970-2001): Emergant and Neglected National Literatures, objavljen 2007. godine. Jedno komparativno ispitivanje epske tradicije u djelima Njegoša i albanskog pisca Đerđa Fište (Gjergj Fishta) pojaviće se iz pera Metjua K. Kertisa (Metthew C. Curtis) te iste 2007. godine pod naslovom: „Petar II Petrović Njegoš i Đerđ Fišta: stvaraoci nacionalnih Epova” („Petar II Petrović Njegoš and Gjergj Fishta: Composers of National Epics), dok tri godine kasnije Svetlana Slapšek objavljuje tekst „Petar II Petrović Njegoš: ikona pesnika sa ikonom“ („Petar II Petrović Njegoš: The Icon of the Poet with the Icon") u knjizi Istorija književnih kultura Istočno-centralne Evrope ( History of the Literary Cultures of East-Central Europe). Neophodno je istaći i rukopis studije Boška Vukčevića: Pe- 
tar Petrović - Njegoš: srpski pjesnik i filozof: rukopis, $n$. D., 2009) (Petar Petrović - Njegoš: Serbian Poet and Philosopher: typescript, $n$. D., 2009) koji je pohranjen u Huver Institutu.

Najšira recepcijska putanja, kao što smo istakli, u ovom periodu okuplja one tekstove o Njegošu i njegovom djelu koji ih osvjetljavaju iz ugla istorije, politike, religije i kulture ${ }^{1}$. Posmatrana hronološki, već 1995. godina donosi istorijsku bilješku o Njegošu iz pera Zorke Milić u njenoj antropološkoj studiji Tuđa večera. Godinu dana kasnije A. Majkl Sels (Michael A. Sells) piše o istrazi poturica u svojoj studiji Izdaja Mosta: religija $i$ genocid u Bosni (The Bridge Betrayed: Religion and Genocide in Bosnia). Raspad Jugoslavije, Njegoš i njegovo djelo i njihov uticaj na savremenu političku istoriju, postaće čest predmet istraživanja američkih autora i u narednom periodu. ${ }^{2}$ Iste godine Džordž L. Šeper (George L. Scheper)

1 Značajno je pomenuti i jedan broj studija koje ispituju Njegoševo djelo i njegov uticaj na oblikovanje različitih segmenata savremene kulture, pogotovo religije. Ger Duijzings u svojoj studiji Religion and the Politics of Identity in Kosovo piše o Gorskom vijencu (2000). O Njegoševoj kapeli na Lovćenu može se naći osvrt Vjekoslava Perice u studiji Balkan Idols: Religion and Nationalism in Yugoslav States. (2002) Gorski vijenac i istraga poturica pominju se u izboru tekstova koji je uredio Aleksandar Laban Hinton Annihilating Difference: The Anthropology of Genocide. (2002) Kratak osvrt na Gorski vijenac može se sresti u izboru radova Religion and the Creation of Race and Ethnicity, koji je uredio Krejg R. Prentis. (2003) Iste godine Njegoš se pominje u zborniku radova The New Crusades: Constructing the Muslim Enemy, koji su uredili Emran Kurejši i Majkl Sels. Mitja Velikonja piše o Njegošu i Gorskom vijencu u studji Religious Separation and Political Intolerance in Bosnia-Hercegovina. (2003)

2 U ovom periodu izdvaja se značajan broj tekstova koji ispituje odnos nacionalnog i političkog: Endru Vahtel piše o Gorskom vijencu u knjizi Making a Nation, Breaking a Nation: Literature and Cultural Politics in Yugoslavia. (1998) O Luči mikrokozma i Gorskom vijencu pišu Viktor Rodometof i Roland Robertson u djelu Nationalism, Glabalisation, and Orthodoxy: The Social Origins of Ethnic Conflict in the Balkans. (2001) Kratak osvrt na Njegoša i Gorski vijenac može se sresti i u djelu Kristofera Kejtvuda: Why the Nations Rage: Killing in the Name of God. (2002) Ben Fokes opisuje Njegoša kao najvećeg epskog pjesnika svih Južnih Slovena u studiji Ethnicity and Ethnic Conflict in the Post-Communist World. (2002) Njegoš se pominje i u izboru tekstova Normana M. Nejmarka: Fires of Hatred: Ethnic Cleansing in Twentieth-Century Europe. (2002) Etničko čišćenje na Balkanu gotovo redovno prepoznaje ulogu Gorskog vijenca u tekstu, kao u knjizi Ethnic Cleansing in the Balkans: Nationalism and the Destruction of Tradition. (2002) Godine 2004. javlja se i jedna komparativna studija iz pera Ilijeve Emilove: Romul's Nations: Myths of Brotherhood and Fratricide in Russian and 
objavljuje rad u kome se bavi sada već čestom temom, etničkim čišćenjem, u radu: "Odjeci Kosovskog boja: Gorski vijenac i etničko čišćenje" ("Reverberations of the Battle of Kosovo: The Mountain Wreath and Ethnic Cleansing"), koji objavljuje u Zborniku Savjest čovječanstva: književnost i traumatsko iskustvo. (The Conscience of the Humankind: Literature and Traumatic Experiences). Naredne godine P. H. Lojta (P. H. Liotta) na sličan način dotiče se Njegoša i uloge njegovih djela u savremenom političkom trenutku u studiji Rasčlanjivanje države: smrt Jugoslavije i zašto je to važno (Dismembering the State: The Death of Yugoslavia and Why It Matters). Godine 2001. i 2002. najplodnije su po broju pomena, tekstova i komentara. Olga S. Opfel (Olga S. Opfell) u svojoj knjizi Kraljevstvo koje čeka (Royalty Who Wait) piše o Njegošu kao o poznatom pjesniku koji je vladao dvadest i jednu godinu i modernizovao Crnu Goru. Njegoš nalazi mjesto još u jednoj enciklopediji: Enciklopedija nacionalizma (Encyclopedia of Nationalism), dok Gorski vijenac odjekuje u istorijskoj studiji Kristofera Merila (Christopher Merrill): Samo bodlje ostadoše: Scene iz balkanskih ratova (Only the Nails Remain: Scenes from the Balkan Wars). Tomas Fleming (Tomas Fleming) piše o Njegošu i savremenoj Crnoj Gori kao o podijeljenoj zemlji 2002. godine u okviru svoje studije Crna Gora: podijeljena zemlja (Montenegro: The Divided Land). Istorija Njegoševog doba je predmet interesovanja i studije Nataše Margulis (Natasha Margulis): Njegoševa Crna Gora: velike sile i modernizacija Balkana: 18301851 (Njegošs Montenegro, the Great Powers, and Modernization in the Balkans: 1830-1851). Kratak opis borbe Crnogoraca i Turaka dat je u tekstu "GORSKI vijenac" ("MOUNTAN Wreath") koji je uključen u izbor tekstova o temi: Hoće li genocid ikada prestati? (Will Genocide Ever End?), koji su uredili grupa autora predvođeni Karolom Ritnerom. Gorski vijenac se pominje i u izboru eseja Kemala H. Karpata (Kemala H. Karpa-

South Slavic National Narratives i tekst Endrua B. Vahtela u zborniku radova pod naslovom: Ideologies and National Identities: The Case of Twentieth-Century Southwestern Europe. (2005) Majkl Gesler pominje Luču Mikrokozma i Gorski vijenac u svojoj studiji National Symbols, Fractured Identities: Contesting the National Narrative. Godine 2007. Nik Miler piše o Gorskom vijencu u svojoj studiji The Nonconformists: Culture, Politics and Nationalism, a Serbian Intellectual Circle, 1994-1991. Kratka bilješka o Njegošu kao vladaru Crne Gore uključena je 2000. u enciklopediju koju je uredio Ričard Fruht Encyclopaedia of Eastern Europe: From the Congress of Vienna to the Fall of Communism. 
ta) Studije o otomanskoj socijalnoj i političkoj istoriji (Studies on Ottoman Social and Politica History). Istorijske prilike za vrijeme vladavine Petra II Petrovića Njegoša ispituju se izboru tekstova Balkanski ratovi: osvajanje i odmazda od otomanske ere do dvadesetog vijeka i dalje (The Balkan Wars: Conquest, and Retribution from the Ottoman Era to the Twentieth Century). Par stranica posvećuje mu i Džon K. Koks (John K. Cox) u svojoj Istoriji Srbije (History of Serbia).

2004. godina donosi nekolike značajne studije iz kulture o kojima će biti posebno riječi, kao i tek poneku bilješku, kao npr. Ričard K. Fruhtovu (Richard C. Frucht) o Luči i Gorskom vijencu u studiji Istočna Evropa: uvod u narode, zemlje $i$ kulturu (Eastern Europe: An Introduction to the People, Lands, and Culture). Zlatar Zdenko naredne godine objavljuje knjigu: Njegoševa Crna Gora: epska poezija, krvna osveta i sukobi u plemenskoj zoni, 1830-1851 (Njegošs Montenegro: Epic Poetry, Blood Feud and Warfare in a Tribal Zone, 1830-1851). Te iste godine Elizabet Roberts (Elizabeth Roberts) pozabaviće se Crnom Gorom pod Njegoševom vlašću u tekstu "TEŽINA otpora: Crna Gora pod Njegošem, 1830-51" ("CRUCIBLE of resistance: Montenegro under Njegoš, 1830-51) koji je objavljen u okviru studije: Carstvo Crne planine: istorija Crne Gore. (Realm of the Black Mountain: History of Montenegro). Iste godine o Njegoševim djelima ponovo piše Zdenko Zlatar u knjizi Poetika Slovenstva: mitopoetske osnove Jugoslavije (The Poetics of Slavdom: The Mythopoetic Foundations of Yugoslavia) ${ }^{3}$. Tek 2007. godine Njegoš ulazi u Antologija srpske književnosti (An Anthology of Serbian Literature), koju su uredili Vasa D. Mihajlović i Branko Mikašinović.

Njegoš se u političkom kontekstu pominje i 2008. godine u knjizi koju su uredili Lenard J. Koen (Lenard J. Cohen) i Jasna Dragović Šošo: Slom država u Južno-istočnoj Evropi: nove perspektive na dezintegraciju Jugoslavije (State Collapse in South-Eastern Europe: New Perspectives

3 Identitet: Bilješka o Gorskom vijencu može se naći izboru tekstova The Politicization of Islam: Reconstructing Identity, State, Faith, and Community in the Late Ottoman State. (2000) Njegoš se pominje i u zborniku tekstova State Identities and the Homogenisation of Peoples, urednik: Heder Rej. (2002) Nezaobilazan uvid u ispitivanje identiteta daje Srđa Pavlović u knjizi Literature, Social Politics, and Identity Construction in Montenegro. (2003) Endrju Hamond piše o Njegošu i Gorskom vijencu u svojoj studiji The Balkans and the West: Constructing the European Other. (2004) 
on Yugoslavia's Disintegration), kao i u knjizi Emila Kerenjija: Jevrejski građani Socijalističke Jugoslavije: politika jevrejskog identiteta u socijalističkoj državi, 1994-1974 (Jewish Citizens of Socialist Yugoslavia: Politics of Jewish Identity in a Socialist State, 1944-1974). Jedan duži tekst o istoriji Crne Gore pojaviće se u časopisu Svijet Srba (Serb World), da bi se $\mathrm{u}$ istom časopisu naredne godine o Božiću pojavio odlomak iz Gorskog vijenca.

Nakon ovog šturog popisa bibliografskih jedinica, vratimo se studiji Svetozara Koljevića Njegoš u engleskoj i američkoj kulturi ne bi li uhvatili nit sa predstavljenom bibliografskom građom! U susretu ovih kultura Koljević prepoznaje svojevrsnu igru ,prevodjenja“! Tome možemo slobodno dodati i duh jednog Valtera Benjamina koji vidi prevođenje kao jednu veliku metaforu tumačenja značenja kulturoloških markera. Ta igra se prevashodno odvija na antropološkom, istorijskom, religioznom i političkom planu. (Koljević, 1999: 7-9) To nam ilustruje sam popis bibliografskih jedinica, pogotovo u periodu od 1995! Pod ovom sjenkom odvija se igra tumačenja Njegoša, kao što je već istaknuto, sve od pojave Mihailovićevog prevoda Gorskog vijenca i Gojine Sablje i pjesne (1995) da bi se, kako nam recepcijski tokovi u ovom istraživanju pokazuju, ponovo zaigralo zahvaljujući ratu 1991-2 koji je izazvao raspad Jugoslavije. Rat je pomjerio akcenat istraživanja sa književnosti na kulturu! Kultura, šta god ona podrazumijevala: naciju, identitet, nacionalizam, etničko čišćenje, drugost, religiju, krvnu osvetu, genocid, državu, politiku, traumu ponovo je nadkrilila Njegoša i njegovo djelo u periodu od 1995. godine. Kao da se krug zatvario!

Ovo na specifičan način uočavaju i američki istraživači. Tako, Elizabet Roberts u pomenutoj istoriji Carstvo Crne planine: istorija Crne Gore u poglavlju "TEŽINA otpora: Crna Gora pod Njegošem, 1830-51" ističe politički značaj Gorskog vijenca u istoriji srpskog naroda i dodaje da je tek odnedavno ,ugled Njegoša i njegove poezije došao pod udar jer su kritičari povezivali anti-muslimansku retoriku Gorskog vijenca sa etničkim čišćenjem i bratoubilačkim ubistvima počinjenim od strane srpskih ekstremista u većini skorašnjih ratova na Balkanu“. (Roberts, 2007: 187-8) Iako ne osporava ulogu nekritičkog recikliranja prošlosti u oblikovanju nacionalne svijesti na Balkanu, Elizabet Roberts prepušta to pitanje istraživačima kulture, dok se ona opredjeljuje za istraživanje Njegoša i njegovog djela s pozicija istorije u kontekstu njegovog vremena i prostora.

O čemu se zapravo ovdje radi? Radi se o svojevrsnom "zlostavlja- 
nju Gorskog vijenca”, kako bi to nazvala Jasmina Ahmetagić reagujući na tekst Esada Bajtala "Gorski vijenac kroz prizmu postgenocidnog iskustva Srebrnice", na neodrživost njegovog tumačenja. Iz niza tekstova od strane američkih autora koji na sličan način "zlostavljaju” Gorski vijenac izdvojićemo ogled Margaret Besindžer iz njene već pomenute studije "Ep, rod i nacionalizam: razvoj balkanske književnosti devetnaestog vijeka" u kome s feminističke pozicije tumači Gorski vijenac i pokazuje da "iako je inspirisan folklornim žanrom, sadrži nacionalističke poruke koje su poslužile političkoj agenda muške populacije". (Beissenger, (1999: 74) Autorka podsjeća da je tekst objavljen 1847. godine, potom da se smatra Njegoševim najvećim djelom i da zauzima ugledno mjesto u srpskom kanonu. Gorski vijenac je, Besindžerova tvrdi, odigrao važnu ulogu u jačanju "srpske nacionalističke kulture, posluživši kao sveti tekst koji je stvorio književnu osnovu nacionalističke ideologije". (1999: 74). Nakon opisa osnovne dramske situacije u djelu, Besindžerova prosto i neutemeljeno zaključuje: "Paralele sa etničkim čičćenjem u bivšoj Jugoslaviji očigledne su." (1999: 74).

Ovim tekstovima pridružuje se tekst Endrua Vahtela (Andrew B. Watchel) "Kako koristiti klasično djelo: Petar Petrović Njegoš u dvadesetom vijeku" (How to Use a Classic: Petar Petrović Njegoš in the Twentieth Century) koji identifikuje Njegoša kao nacionalnog pisca Srba, Jugoslovena i Crnogoraca, što, kako kaže, "reflektuje izazovnu prirodu nacionalnog identiteta u zemljama bivše Jugoslavije, baš kao što ukazuje na izvještačenost dopuštanja jednom jedinom pjesniku da predstavlja cijelu naciju" (Watchel, 2004: 132). Predstavljajući Njegoša kao izuzetnu figuru, Vahtel ističe da je on postavio osnove za modernu južno-slovensku književnost svojim Gorskim vijencom, epom u dramskoj formi, koji je prepoznat kao nacionalni ep Crne Gore, Srbije i prve i druge Jugoslavije. U novije vrijeme, međutim, taj isti ep tumači se i kao podroban plan za etničko čišćenje, zbog čega je izbačen iz školskih programa Bosne i Hercegovine. Vahtel podsjeća da u se u Crnoj Gori prema Njegošu ophodili kao prema sekularkom svecu te je njegovo tijelo ekshumirano i sahranjivano mnogo puta od njegove smrti 1851. godine od strane onih koji su htjeli da upotrijebe Njegoša i njegovo djelo za svoje nacionalne i političke namjene: definisanje jugoslovenskog, srpskog i crnogorskog identiteta. Vahtel, prateći transformisanje Njegoša u jugoslovenskog pisca, prepoznaje kompleksnost tog 
procesa tvrdeći da nijedan pisac ne može postati nečiji pukim dekretom i da ga je "možda samo Andrić mogao uvesti u jugoslovenski kanon a da ne naruši suštinu njegovog mjesta u književnosi" (2004: 139), što on ipak nije učinio.

U odbranu Njegoševog Gorskog vijenca optuženog da predstavlja podrobni plan etničkog čišćenja u novije vrijeme staje, između ostalih, Metju Kertis u već pomenutoj obimnijoj komparativnoj studiji „Petar II Petrović Njegoš and Đerđ Fišta: stvaraoci nacionalnih epova”. Njegoš i Fišta su, kako Kertis kaže, adaptirali i odbacili usmenu narativnu tradiciju i stvorili samo-svjesno konstrusanu poeziju i time se suprotsavili porukama usmenih epova svoje zajednice. Iako su često namjerno preuzimali simbole i mitove iz prošlosti i imitirali jezik usmene poezije, ipak su stvorili prefinjena djela u kojima su integrisali tekuće događaje i savremenu filozofiju u svoje djelo. I Njegoš i Fišta portretisali su svoju kulturu kao nacionalnu kulturu, pri čemu su preispitivali tradicionalne društvene organizacije, i time rafinirali društvene vrijednosti i čak prilagođavali etički kod u svojim zajednicama. Kertis potencira da se njegovo tvrđenje neće dopasti onima koji vide Njegoševu poemu kao „podroban plan za etničko čišćenje“ ili kao „himnu genocidu“, (Metthew, 2007) što opet ne znači da oba epa nisu puna nasilja, i da to umanjuje njihov potencijal za konstruisanje humanog ideala nacije.

Možemo li na kraju ovog pregleda najnovije recepcije Njegoša u Americi, u kome smo ustanovili dominantnost kulture, prije svega politike, nad književnošću, naprosto izraziti nadu u kojoj odjekuje davni eho Milana Bogdanovića da će se Njegoš ponovo vratiti carstvu književnosti, ali i nadu da će vremenom izblijediti one kritičke pozicija iz kojih odjekuju glasovi koji tumače Njegoša izvan kulturno istorijskog konteksta u kome su njegova djela nastala, a sa ciljem da postignu određeni politički cilj?

\section{Literatura}

Ahmetagić, J. (2011). Priče o Narcisu zlostavljaču: zlostavljanje $i$ književnost. Beograd: Službeni glasnik.

Beissinger. M. (1999). "Epic, Gender, and Nationalism: The Development of Nineteenth-Century Balkan Literature" in Epic Traditions in the 
Contemporary World: The Poetics of Community. Eds. M. Beissinger, J. Tylus, and A. Wofford. University of California Press.

Curtis, M. (2007). „Petar II Petrović Njegoš and Gjergj Fishta: Composers of National Epics“. The Carl Beck Papers in Russian and East European Studies.

Ignjačević, S. (1997). „Naša recepcija afričke književnosti engleskog izraza“". Language and Literature at the End of XX Century". Podgorica: Institut za strane jezike.

Koljević, S. (1999). Njegoš u engleskoj i američkoj kulturi. Podgorica: Oktoih. Roberts, E. (2007). Realm of the Black Mountain: A History of Montenegro. Watchel, A. B. (2004). "How to Use a Classic: Petar Petrović Njegoš in the Twentieth Century" in Ideologies and National Identities, John Lampe and Mrk Mazower (Eds.). CEU Press.

\section{Izvori}

Brajović, T. (2007). Identično i različito. Beograd: Geopoetika.

Goy, E. D. (1995). The Sabre and the Song. Serbian P.E.N. Publications.

Deretić, J. (1969). Kompozicija Gorskog vijenca. Beograd: Zavod za izdavanje udžbenika.

Đilas, M. (1966). Njegoš: Poet, Prince, Bishop, New York: Haircourt, Brace \& World, Inc.

Đurić, V. (1999). Njegoševa poetika, Podgorica: Oktoih.

Lompar, M. (2010). Njegoševo pesništvo, Beograd: Srpska književna zadruga. Lompar, M. (2010). O tragičkom pesniku, Beograd: Albatros Plus.

Petronijevć, B. (1999). Filozofija u Gorskom vijencu, Podgorica: Oktoih, 1999.

Popović P. (1999). O Gorskom vijencu, Podgorica: Oktoih.

Sekulić, I. (2009). Njegošu: knjiga duboke odanosti, Beograd: Ethos.

Velimirović N. (1921). Religija Njegoševa, Beograd: S. Cvijanović.

Vukčević, Z. (2005). Frekvencijski rečnici Gorskog vijenca i Luče mikrokozma, Podorica: Crnogorska akademija nauka i umjetnosti. 
Radojka Vukčević

\section{Summary}

\section{THE LATEST RECEPTION OF NJEGOŠ IN USA: 1995-2010}

The paper explores the latest reception tendencies of Njegoš's works in the USA with equal emphases on American translations of his works, and critical responses of American scholars to his works and himself. This research will follow Svetozar Koljević's conclusions he came to in his pivotal study Njegos in English and American Cultue (Njegoš u engleskoj i američkoj kulturi), and consequently the accent will be put on the period after 1995. Chronological method will be applied, followed by effort of evaluating American contributions from the point of view of the present reception tendencies. 